\title{
PERHITUNGAN BIAYA PENDIDIKAN MENGGUNAKAN METODE TRADISIONAL DAN ACTIVITY BASED COSTING DI SMK
}

\section{EDUCATION COST CALCULATION USING TRADITIONAL AND ACTIVITY BASED COSTING FOR VOCATIONAL SCHOOL}

\author{
Oleh: \\ Arina Chimaya El Haqqi \\ Pendidikan Akuntansi Universitas Negeri Yogyakarta \\ misselchimaya@gmail.com \\ $\underline{\text { Sukirno }}$ \\ Staf Pengajar Jurusan Pendidikan Akuntansi Universitas Negeri Yogyakarta
}

\begin{abstract}
Abstrak
Penelitian ini bertujuan untuk mengetahui hasil perhitungan Biaya Pendidikan yang dihitung menggunakan Metode Tradisional dan Metode Activity Based Costing di SMKN 1 Bantul Tahun 2016. Penelitian ini adalah penelitian deskriptif yang melibatkan pihak-pihak yang mengetahui elemen biaya pendidikan. Data dianalisis menggunakan teknik deskriptif kuantitatif dengan menggunakan tabel, grafik, dan angka. Teknik analisis data dalam penelitian yaitu: 1) menghitung biaya pendidikan menggunakan Metode Tradisional, 2) menghitung biaya pendidikan menggunakan Metode Activity Based Costing, dan 3) membandingkan hasil perhitungan berdasarkan kedua metode.
\end{abstract}

Kata kunci: Metode Tradisional, Metode Activity Based Costing, Biaya Pendidikan

\begin{abstract}
This study aims to calculate education cost using traditional and activity based costing method and also to compare education cost calculation based on both methods. This study was a descriptive research involved stakeholders knowing about education cost elements. Data were analyzed with descriptive quantitative technique using table, graph, and number. Costing procedures were 1) calculating education cost using Traditional Based Costing Method for every Student at each Major and Class X, XI, and XII per month, 2) calculating education cost using Traditional Based Costing Method for every Student at each Major and Class X, XI, and XII per month, and 3) comparing the result between two methods.
\end{abstract}

Keywords: Traditional Based Costing, Activity Based Costing, Education Cost

\section{PENDAHULUAN}

Pendidikan menjadi hal yang penting bagi setiap individu, baik pendidikan formal, informal, maupun nonformal. Tidak jarang pendidikan dijadikan tolok ukur kesejahteraan seseorang. Bahkan saat ini, di Pariaman, tingkat pendidikan menjadi penentu uang jemputan (uang yang diberikan mempelai wanita kepada calon suami) (Muslim, 2015: 72). Hal tersebut menunjukkan bahwa masyarakat mulai memperhitungkan tingkat pendidikan dan menyadari seberapa penting pendidikan.

Pembangunan pendidikan pada dasarnya sama pentingnya dengan pembangunan ekonomi (Mulyono, 2010: 22). Artinya, urgensi peningkatan pendidikan sama dengan peningkatan pembangunan ekonomi, sehingga pendidikan menjadi bidang yang harus terus dikaji dan dikembangkan. Pendidikan yang bagus akan melahirkan sumber daya manusia yang kompeten 
sehingga akan membantu pembangunan perekonomian negara. Oleh karena itu, pelaksanaan pendidikan di Indonesia harus direncanakan dengan matang dan dilaksanakan dengan sebaik-baiknya, sehingga dapat menghasilkan generasi penerus bangsa yang kompeten.

Salah satu komponen dalam pelaksanaan pendidikan adalah sistem pendidikan. Sistem pendidikan yang baik dibangun dengan perencanaan yang baik. Artinya, pemerintah dan pihak yang terkait dengan dunia kependidikan harus merencanakan dengan matang mengenai pelaksanaan proses pendidikan. Perencanaan pendidikan dapat digunakan untuk mencapai tujuan pendidikan dengan lebih efektif dan efisien serta dapat digunakan untuk membangun sistem dengan strategi yang tepat Matin (2013: 16).

Saat ini mutu pendidikan di Indonesia masih rendah. Hal ini dapat dilihat dari kurikulum yang belum sesuai dengan karakteristik bangsa Indonesia, kualitas lulusan sekolah yang tidak sesuai dengan harapan masyarakat, guru yang tidak kompeten, sarana dan prasarana yang kurang mendukung, tingginya kesenjangan pelaksanaan pendidikan antardaerah di Indonesia, serta permasalahan lainnya. Pelaksanaan pendidikan di Indonesia belum berjalan dengan efektif dan efisien, sehingga perlu dilakukan peningkatan efisiensi (4th OECD Economic Survey of Indonesia, Maret 2015). Peningkatan efektivitas dan efisiensi harus dilakukan untuk meningkatkan mutu pendidikan di Indonesia.

Ketika membicarakan mengenai mutu pendidikan maka tidak terlepas dari dana atau biaya pendidikan. Biaya pendidikan merupakan salah satu komponen masukan instrumental yang penting dalam penyelenggaraan pendidikan (Supriadi, 2014: 3). Pembiayaan pendidikan adalah faktor penting dalam penjaminan mutu dan kualitas pendidikan. Meskipun biaya pendidikan bukan satu-satunya faktor keberhasilan pelaksanaan pendidikan, namun tanpa adanya pembiayaan yang mencukupi, maka pendidikan yang berkualitas tidak akan terlaksana (Mulyono, 2010: 5). Penentuan biaya akan memengaruhi tingkat efisiensi dan efektivitas kegiatan di dalam suatu organisasi (Matin, 2014: 1).

Sekolah sebagai lembaga pendidikan membutuhkan informasi mengenai biaya sebagai bahan pertimbangan untuk pelaksanaan efisiensi biaya. Biaya pendidikan berperan dalam mewujudkan mutu pendidikan dengan dijadikan sebagai acuan untuk menilai efisiensi pelaksanaan pendidikan. Akurasi penetapan biaya pendidikan diperlukan untuk mengetahui apakah kegiatan yang dilakukan oleh sekolah sudah terlaksana dengan efektif dan efisien atau belum. Selain itu, analisis biaya juga dapat digunakan sebagai bahan untuk menganalisis pos mana saja yang terjadi inefisiensi biaya. Oleh karena itu, sekolah sebagai lembaga pendidikan perlu mengetahui informasi mengenai biaya pendidikan secara jelas sebagai dasar pengambilan keputusan.

Dewasa ini, penentuan biaya pendidikan di sekolah masih berdasarkan cara tradisional. Sekolah sebagai lembaga nonprofit seharusnya mempertimbangkan baik-baik mengenai penetapan anggaran biaya pendidikan. Penentuan biaya pendidikan yang tidak tepat akan menyebabkan terjadinya overcosting atau undercosting (Horngren, Datar, \& Foster, 2008: 161). Penentuan biaya yang lebih akurat dapat membantu pemerintah dalam menentukan besarnya bantuan operasional yang akan dianggarkan untuk setiap siswa.

Activity Based Costing adalah sistem akuntansi yang berfokus pada aktivitas organisasi dan pengumpulan biaya-biaya berdasarkan sifat pokok yang masih mendasari (Raiborn \& Kinney, 2011: 150). Dengan menggunakan metode Activity Based Costing, selain berguna bagi pengambilan keputusan, metode ini juga dapat digunakan untuk menentukan jumlah 
biaya yang harus dibebankan oleh sekolah kepada siswa berdasarkan aktivitas yang dilaksanakan. Informasi ini akan berguna untuk mengetahui apakah biaya yang dibebankan kepada siswa sudah pas, berlebihan, atau kurang.

Perbedaan perhitungan biaya pendidikan antara Metode Tradisonal dan Metode Activity Based Cosing perlu dibandingkan untuk mengetahui metode mana yang lebih tepat untuk diterapkan dalam penentuan biaya pendidikan di sekolah. Salah satu cara untuk membandingkan hasil perhitungan biaya penididikan antara Metode Tradisional dan Metode Activity Based Costing adalah dengan membandingkan biaya setiap siswa per paket keahlian per bulan yang masingmasing dihitung dengan kedua metode tersebut.

Beberapa penelitian mengenai perbandingan penerapan Metode Tradisional dan Metode Activity Based Costing di pendidikan tinggi telah dilakukan (Ruhupatty \& Maguad: 2015; Maelah, Amir, \& Ahmad: 2011; AbuTapanjeh: 2008). Hasil penelitian menunjukkan bahwa Activity Based Costing dapat digunakan untuk mencegah, mendeteksi, serta mengestimasi kesalahan internal maupun eksternal dari Cost of Quality (Ruhupatty \& Maguad: 2015). Activity Based Costing menyediakan informasi biaya yang komprehensif dan detail (Maelah, Amir, \& Ahmad: 2011) serta merupakan pendekatan yang kuat dan menguntungkan bagi organisasi nonprofit seperti lembaga pendidikan karena menyediakan informasi yang lebih baik dan akurat (Abu-Tapanjeh, 2008). Implementasi Activity Based Costing pada sekolah menengah telah dilakukan dalam penelitian skripsi (Cahyaningrum: 2015; Andreti: 2015; Setyaningrum: 2015), namun belum dibandingkan dengan perhitungan menggunakan Metode Tradisional. Studi komparasi dua metode ini menunjukkan bahwa Activity Based Costing dapat digunakan untuk pertimbangan pegambilan keputusan mengenai alokasi sumber daya, investasi, penambahan dan pengurangan unit, serta biaya pelayanan (Coskun \& Yilmaz: 2012).

Saat ini, perhitungan Biaya Pendidikan di sekolah masih sangat sederhana. Penentuan biaya pendidikan per siswa di SMKN 1 Bantul disamaratakan untuk setiap tingkat. Padahal aktivitas yang dilakukan siswa setiap paket keahlian berbeda. Biaya SPP untuk siswa kelas X per bulan adalah Rp120.000,00, untuk kelas XI dan XII per bulan adalah Rp100.000,00. Biaya pendidikan yang disamaratakan untuk setiap siswa per tingkat ini bisa jadi mengalami kelebihan maupun kekurangan karena aktivitas yang dilakukan setiap siswa antarpaket keahlian berbeda-beda. Biaya SPP di SMKN 1 Bantul ditentukan dengan cara menjumlah seluruh biaya yang dibutuhkan kemudian dikurangi bantuan operasional dari pemerintah berupa BOS dan BOSDA (sekarang PPA untuk tahun 2017).

Menurut Horngren, Datar, \& Foster (2008: 161) pemerataan biaya dapat menimbulkan overcosting dan undercosting. Overcosting artinya terjadi penetapan biaya yang terlalu tinggi sehingga sebuah produk atau jasa yang dihasilkan membutuhkan sumber daya yang lebih sedikit tetapi justru memiliki biaya per unit yang tinggi. Undercosting artinya terjadi penetapan biaya yang terlalu rendah sehingga biaya yang ditetapkan lebih rendah daripada sumber daya real yang dibutuhkan untuk memproduksi produk atau jasa.

Informasi pengelolaan biaya dan peningkatan efisiensi merupakan komponen penting yang menjadi harapan masyarakat. Sekolah membutuhkan informasi biaya sebagai salah satu dasar pelaksanaan efisiensi. Oleh karena itu, penelitian ini perlu dilakukan untuk mengetahui perbandingan hasil perhitungan biaya pendidikan per siswa per 
Paket Keahlian per bulan di SMK dengan dua metode yang berbeda.

\section{METODE PENELITIAN}

Penelitian ini merupakan jenis penelitian deskriptif dengan pendekatan kuantitatif. Menurut Prasetya \& Jannah (2013: 42), penelitian deskriptif merupakan penelitian yang dilakukan untuk memberikan gambaran yang lebih detail mengenai suatu gejala atau fenomena dengan hasil akhir yang biasanya berupa tipologi atau pola-pola mengenai fenomena yang sedang dibahas.

Bentuk dari penelitian deskriptif ini adalah studi perbandingan (comparative $s t u d y$ ). Studi perbandingan merupakan bentuk penelitian deskriptif yang membandingkan dua atau lebih situasi, kejadian, kegiatan, program, dan sebagainya yang berjenis sama (Sukmadinata, 2015: 79). Dalam penelitian ini yang dibandingkan adalah perhitungan biaya pendidikan dengan menggunakan Metode Tradisional dan Metode Activity Based Costing.

Penelitian dilaksanakan di SMKN 1 Bantul, Jalan Prangtritis Km 11 Sabdodadi, Bantul, Bantul, DIY pada bulan Mei 2017 sampai Desember 2017.

Subjek dalam penelitian ini adalah pihak yang dipandang mampu memberikan informasi mengenai penggunaan biaya pendidikan di SMKN 1 Bantul. Subjek penelitian ini adalah Wakil Kepala Sekolah Bagian Sarana dan Prasarana sebagai narasumber yang mengetahui pengelolaan keuangan sekolah secara keseluruhan.

Objek dalam penelitian ini adalah biaya pendidikan di SMKN 1 Bantul. Seluruh komponen biaya pendidikan yang ada di SMKN 1 Bantul dihitung dengan Metode Tradisional dan Metode Activity Based Costing, kemudian hasil perhitungan dibandingkan untuk mengetahui apakah terjadi undercosting atau overcosting.

Pendekatan yang digunakan adalah pendekatan kuantitatif karena hasil data yang dianalisis menggunakan tabel, grafik, dan angka. Penelitian kuantitatif merupakan penelitian yang memandang kebenaran sebagai sesuatu yang tunggal, objektif, universal, dan dapat diverifikasi (Purwanto, 2015: 164).

Data yang dikumpulkan merupakan data primer dan sekunder yang dikumpulkan melalui wawancara dan dokumentasi. Wawancara dilakukan untuk mengidentifikasi biaya dan aktivitas, sedangkan dokumentasi dilakukan untuk mengumpulkan data sekunder berupa RKAS, pembagian jam mengajar, jam pelajaran, penggunaan ruang, data luas ruangan, dan jam ujian.

Analisis data dibagi menjadi tiga, yaitu 1) menghitung Biaya Pendidikan menggunakan Metode Tradisional yang terdiri dari dua tahap yaitu mengidentifikasi biaya dan menetukan tarif biaya, 2) menghitung Biaya Pendidikan menggunakan Metode Activity Based Costing yang terdiri dari empat tahap (Hansen \& Mowen, 2009: 176-185) yaitu a) identifikasi aktivitas dan atribut aktivitas, b) pembebanan biaya pada aktivitas, c) pengmpulan biaya dalam cost pool, dan d) penentuan dan perhitungan cost driver, serta 3) membandingkan hasil perhitungan menggunakan kedua metode.

\section{HASIL PENELITIAN DAN PEMBA- HASAN}

Metode tradisonal mengasumsikan bahwa biaya dapat diklasifikasikan menjadi biaya tetap dan biaya variabel, sehingga unit produk atau pemicu biaya lainnya berhubungan erat dengan unit yang diproduksi seperti jam tenaga kerja langsung dan jam mesin (Mowen \& Hansen, 2006: 45).

Tahap pertama dalam perhitungan berdasarkan Metode Tradisional adalah identifikasi biaya. Biaya diidentifikasi menjadi Biaya Langsung dan Biaya Tidak Langsung. Biaya Langsung adalah biaya yang digunakan secara langsung untuk kegiatan siswa, sedangkan biaya tidak langsung adalah biaya yang dieluarkan 
untuk kegiatan yang sifatnya menunjan kegiatan siswawa.

Di SMKN 1 Bantul terdapat 42 Biaya Langsung dan 99 Biaya Tidak Langsung. Biaya Langsung kemudian dibebankan ke objek biaya dengan terlebih dahulu menentukan tarif masing-masing biaya.

Biaya Tidak Langsung dikumpulkan menjadi satu kemudian dihitung tarif biaya. Dalam Metode Tradisional, penentuan tarif Biaya Tidak Langsung menggunakan dasar tunggal, yaitu jumlah siswa, sehingga rumus perhitungan tarif Biaya Tidak Langsung adalah sebagai berikut:

Jumlah Biaya Tidak Langsung Jumlah Seluruh Siswa

\begin{tabular}{c} 
Rp6.523.799.338,00 \\
\hline 1488 \\
Rp4.384.273,75
\end{tabular}

Tarif Biaya Langsung dihitung berdasarkan objek yang menggunakan biaya tersebut, contohnya yaitu Biaya Uji Kompetensi Keahlian yang dibebankan pada siswa kelas XII pada setiap Paket Keahlian.

Tahap selanjutnya yaitu membebankan biaya ke objek biaya. Pembebanan ke Objek Biaya didasarkan pada jumlah siswa, sehingga pembebanan dihitung dengan mengalikan biaya dengan jumlah siswa. berikut adalah hasil perhitungan Biaya Pendidikan menggunakan Metode Tradisional.

\section{Tabel 1. Biaya Pendidikan berdasarkan Metode Tradisional}

\begin{tabular}{|l|c|c|c|}
\hline \multirow{2}{*}{\multicolumn{1}{|c|}{ Paket Keahlian }} & \multicolumn{3}{c|}{ Biaya Pendidikan (Rp) } \\
\cline { 2 - 4 } & Kelas X & \multicolumn{1}{c|}{ Kelas XI } & Kelas XII \\
\hline Akuntansi & $694.274,59$ & $781.185,34$ & $837.187,83$ \\
\hline Perbankan Syariah & $684.968,85$ & $771.730,16$ & $652.085,24$ \\
\hline Administrasi Perkantoran & $690.191,25$ & $777.028,43$ & $833.155,33$ \\
\hline Pemasaran & $698.707,87$ & $785.771,16$ & $841.671,94$ \\
\hline Teknik Komputer dan Jaringan & $695.767,17$ & $782.599,64$ & $836.029,31$ \\
\hline Multimedia & $695.292,37$ & $782.053,68$ & $835.632,78$ \\
\hline Rekayasa Perangkat Lunak & $695.586,21$ & $782.423,39$ & $660.782,43$ \\
\hline
\end{tabular}

Biaya Pendidikan untuk Setiap Siswa di Kelas X dan XI, untuk setiap Paket Keahlian berdasarkan Metode Tradisional tidak memiliki perbedaan yang signifikan. Biaya paling rendah dibebankan pada Paket Keahlian Perbankan Syariah dan biaya paling tinggi pada Paket Keahlian. Siswa Perbankan Syariah yang berjumlah paling sedikit dibandingkan dengan jumlah siswa di Paket Keahlian lain dibebani biaya yang lebih kecil. Hasil penelitian ini sejalan dengan hasil penelitian oleh Martusa dan Mariam (2012) dan Rumampuk (2013) yang menemukan bahwa produk yang volume produksinya lebih sedikit akan dibebani porsi biaya yang lebih kecil.
Jumlah siswa Paket Keahlian Pemasaran lebih kecil daripada siswa Paket Keahlian Akuntansi, namun siswa Pemasaran dibebani biaya yang lebih tinggi daripada siswa Pemasaran Kelas $\mathrm{X}$ dibebani biaya paling tinggi dibandingkan Paket Keahlian Akuntansi dan Paket Keahlian lain karena biaya pelaksanaan pembelajaran produktif untuk Paket Keahlian ini lebih tinggi dibandingkan dengan Paket Keahlian lain, yaitu sebesar Rp378.006,87 per siswa. Jumlah tersebut cukup berpengaruh pada hasil perhitungan Biaya Pendidikan Berdasarkan Metode Tradisional. Jumlah biaya yang dibebankan tidak selalu tergantung pada jumlah volume produksi, namun dapat dipengaruhi 
oleh biaya lain yang dibebankan khusus untuk Paket Keahlian atau kelas tertentu. Hal ini sejalan dengan hasil penelitian oleh Kumar dan Mahto (2013) yang menemukan bahwa jumlah volume produksi bukan merupakan faktor utama yang mempengaruhi hasil perhitungan berdasarkan Metode Tradisional.

Selisih antara biaya terkecil dan terendah pada kelas XII cukup tinggi, yaitu sebesar Rp189.586,71. Biaya yang dibebankan pada siswa Perbankan Syariah dan Rekayasa Perangkat Lunak cenderung lebih rendah dibandingkan Paket Keahlian lainnya. Hal ini terjadi karena pada tahun 2016 belum ada siswa kelas XII yang mengikuti ujian pada Paket Keahlian tersebut, sehingga kedua Paket Keahlian ini tidak dibebani biaya yang digunakan untuk pelaksanaan ujian kelas XII, seperti Ulangan Akhir Semester Genap, Uji Kompetensi Keahlian dan Ujian Nasional.

Activity-Based Costing adalah metode pembebanan biaya yang didesain untuk menyediakan informasi biaya sebagai dasar pengambilan keputusan baik strategis maupun keputusan lain yang memengaruhi kapasitas (Noreen, Brewer, \& Garrison: 2008: 235).
Tahap perhitungan yang digunakan adalah tahap perhitungan oleh Hansen \& Mowen (2009: 176-185).

Tahap pertama dalam metode ini adalah identifikasi Aktivitas dan Atribut Aktivitas. Berdasarkan Metode ABC, aktivitas dibagi menjadi dua yaitu aktivitas primer dan sekunder. Aktivitas primer merupakan aktivitas yang digunakan oleh siswa, sedangkan aktivitas sekunder merupakan aktivitas digunakan oleh aktivitas aktivitas lainnya (Hansen \& Mowen, 2009: 179). Total Biaya Pendidikan di SMKN 1 Bantul adalah Rp13.583.016.848,00. Dari jumlah tersebut 23,08\% merupakan Aktivitas Primer dan 76,92\% merupakan Aktivitas Sekunder.

Setelah dilakukan identifikasi Aktivitas, biaya-biaya di SMKN 1 Bantul yang berjumlah 141 jenis biaya dibebankan ke setiap aktivitas yang terdiri dari dua puluh sembilan aktivitas dan empat activity cost pool. Pembebanan yang pertama adalah pembebanan biaya sumber daya ke aktivitas yang dihitung berdasarkan resource consumption cost driver. Pembebanan kedua adalah membebankan Aktivitas Sekunder ke Aktivitas Primer sesuai dengan konsumsi aktivitas. Berikut adalah rincian biaya aktivitas di SMKN 1 Bantul tahun 2016.

Tabel 2. Aktivitas di SMKN 1 Bantul

\begin{tabular}{|l|r|}
\hline \multicolumn{1}{|c|}{ Jenis Biaya } & Jumlah Biaya (Rp) \\
\hline Aktivitas Administrasi, Pelaporan, Transportasi & 55.444 .000 \\
\hline Aktivitas Penyusunan Perangkat Administrasi Kelas & 9.607 .000 \\
\hline Aktivitas Belajar Mengajar untuk Seluruh Siswa & 126.871 .786 \\
\hline Aktivitas Pembelajaran Produktif & 469.000 .000 \\
\hline Aktivitas Pembelajaran Fisika & 11.520 .000 \\
\hline Aktivitas Belajar Mengajar untuk Kelas X & 46.000 .000 \\
\hline Aktivitas Belajar Mengajar untuk Kelas XI & 617.890 .000 \\
\hline Aktivitas Belajar Mengajar untuk Kelas XII & 128.294 .000 \\
\hline Aktivitas Kegiatan Ekstrakurikuler & 108.280 .000 \\
\hline Aktivitas Ujian Semester Ganjil 2016/2017 & 160.290 .000 \\
\hline Aktivitas Ujian Semester Genap 2015/2016 & 100.260 .000 \\
\hline Aktivitas Uji Kompetensi Keahlian & 107.088 .940 \\
\hline
\end{tabular}


Jurnal Pendidikan Akuntansi Indonesia, Vol. XVI, No. 1, Tahun 2018 Arina Chimaya El Haqqi \& Sukirno $35-47$

\begin{tabular}{|l|r|}
\hline \multicolumn{1}{|c|}{ Jenis Biaya } & Jumlah Biaya (Rp) \\
\hline Aktivitas Ujian Sekolah dan Ujian Nasional Online & 199.343 .620 \\
\hline Aktivitas Jasa dan Kegiatan Sosial & 1.182 .315 .820 \\
\hline Aktivitas Kesiswaan untuk Seluruh Siswa & 573.045 .000 \\
\hline Aktivitas Kesiswaan Khusus Siswa Kelas X & 52.330 .000 \\
\hline Aktivitas Kesiswaan Khusus Siswa Kelas XI & 10.000 .000 \\
\hline Aktivitas Kesiswaan Khusus Siswa Kelas XII & 395.878 .000 \\
\hline Aktivitas Pembiayaan Tenaga Kependidikan & 924.347 .000 \\
\hline Aktivitas Manajemen Sekolah & 695.300 .064 \\
\hline Aktivitas Pembiayaan Sewa Tanah, Listrik, Internet, Telepon & 295.800 .000 \\
\hline Aktivitas Pembangunan Fisik & 952.240 .000 \\
\hline Aktivitas Pengembangan Kurikulum & 15.915 .000 \\
\hline Aktivitas Pengembangan Silabus & 46.341 .000 \\
\hline Aktivitas Pengembangan SDM & 252.022 .400 \\
\hline Aktivitas Pengadaan Sarana Prasarana & 1.002 .078 .310 \\
\hline Aktivitas Pemeliharaan Sarana Prasarana & 1.011 .412 .808 \\
\hline Aktivitas Unit Produksi & 21.228 .000 \\
\hline Aktivitas Pembiayaan Tenaga Pendidik & 3.994 .136 .100 \\
\hline Aktivitas Bimbingan Konseling & 18.738 .000 \\
\hline
\end{tabular}

Salah satu cara untuk mengurangi kerumitan perhitungan Biaya Pendidikan berdasarkan Metode Activity Based Costing menurut Hansen \& Mowen (2009; 186) adalah dengan mengumpulkan aktivitas dengan rasio konsumsi yang sama ke dalam suatu kelompok biaya (Cost Pool). Oleh karena itu, Aktivitas yang ada di dalam Aktivitas Belajar Mengajar dan Kesiswaan dikelompokkan dalam empat cost pool yaitu, Activity Cost Pool Belajar Mengajar untuk Seluruh Siswa, Belajar Mengajar Tiap Paket Keahlian, Belajar Mengajar Tiap Kelas, dan Kesiswaan untuk Seluruh Siswa.
Tahap akhir dari Activity Based Costing adalah membebankan biaya pada produk, dalam hal ini yaitu siswa karena siswa merupakan penikmat jasa yang dihasilkan oleh sekolah. Sebelum dibebankan kepada siswa, terlebih dahulu dilakukan perhitungan tarif biaya dari aktivitas primer sesuai dengan proporsi aktivitas penggunaan (Hansen \& Mowen, 2009: 181).

Rumus perhitungan tarif aktivitas yaitu:

$\frac{\text { Jumlah Biaya Aktivitas }}{\text { Cost Driver }}$

Tabel 3. Penentuan Cost Driver

\begin{tabular}{|l|l|}
\multicolumn{1}{|c|}{ Aktivitas } & \multicolumn{1}{c|}{ Cost Driver } \\
\hline $\begin{array}{l}\text { Activity Cost Pool Belajar Mengajar untuk Seluruh } \\
\text { Siswa }\end{array}$ & Jumlah Jam Belajar Siswa \\
\hline Aktivitas Pembelajaran Produktif & $\begin{array}{l}\text { Jumlah Siswa Tiap Paket } \\
\text { Keahlian }\end{array}$ \\
\hline Activity Cost Pool Belajar Mengajar Tiap Paket & Jumlah Paket Keahlian \\
\hline
\end{tabular}


Jurnal Pendidikan Akuntansi Indonesia, Vol. XVI, No. 1, Tahun 2018 Arina Chimaya El Haqqi \& Sukirno

$35-47$

\begin{tabular}{|l|l|}
\hline Keahlian & \\
\hline Bimbingan Konseling & Jumlah Jam BK \\
\hline Pembelajaran Fisika & Jam Pelajaran Fisika \\
\hline Activity Cost Pool Belajar Mengajar Tiap Kelas & Jumlah Kelas \\
\hline Belajar Mengajar untuk Kelas X & Jam belajar Siswa kelas X \\
\hline Belajar Mengajar untuk Kelas XI & Jam belajar Siswa kelas XI \\
\hline Belajar Mengajar untuk Kelas XII & Jam belajar Siswa kelas XII \\
\hline Ujian Semester Ganjil 2016/2017 & Jam Ujian Semester Ganjil \\
& 2016/2017 \\
\hline Ujian Semester Genap 2015/2016 & Jam Ujian Semester Genap \\
\hline Uji Kompetensi Keahlian & Ja15/2016 \\
\hline Ujian Sekolah dan Ujian Nasional Online & Jam Ujian Sekolah dan UN \\
\hline Pembiayaan Tenaga Pendidik & Jumlah Jam Mengajar \\
\hline Pengembangan Sumber Daya Manusia & Jumlah Guru Tiap Paket Keahlian \\
\hline Pengembangan Kurikulum & Jumlah Paket Keahlian x Tingkat \\
\hline Pengembangan Silabus & Jumlah Mata Pelajaran \\
\hline Manajemen Pengetahuan Umum & Jumlah Jam Pelajaran \\
& Pengetahuan Umum \\
\hline Manajemen Penelitian dan Pengembangan & Jumlah Seluruh Siswa \\
\hline Kegiatan Ekstrakurikuler & Jumlah Siswa Kelas X dan XI \\
\hline Activity Cost Pool Kesiswaan untuk Seluruh Siswa & Jumlah Seluruh Siswa \\
\hline Kesiswaan Khusus Siswa Kelas X & Jumlah Siswa Kelas X \\
\hline Kesiswaan Khusus Siswa Kelas XI & Jumlah Siswa Kelas XI \\
\hline Kesiswaan Khusus Siswa Kelas XII & Jumlah Siswa Kelas XII \\
\hline Pembiayaan Unit Produksi & Jumlah Paket Keahlian \\
\hline Pembiayaan Jasa dan Kegiatan Sosial & Jumlah Seluruh Siswa \\
\hline & \\
\hline
\end{tabular}

Setelah menentukan tarif aktivitas kemudian biaya dibebankan ke aktivitas berdasarkan tarif aktivitas dikalikan dengan activity consumption cost driver. Sebagai contoh, Aktivitas Belajar Mengajar untuk Kelas X dibebankan ke kelas X pada setiap Paket Keahlian berdasarkan jam belajar. Pada Paket
Keahlian Akuntansi kelas X, jam belajar adalah 415 jam, sehingga

pembebanannya yaitu :

Rp27.660,85 x $415=$ Rp11.479.254,36

Berikut adalah hasil perhitungan Biaya Pendidikan di SMKN 1 Bantul tahun 2016 berdasarkan Metode Tradisional.

Tabel 4. Biaya Pendidikan di SMKN 1 Bantul berdasarkan ABC

\begin{tabular}{|l|c|c|c|}
\hline \multirow{2}{*}{\multicolumn{1}{|c|}{ Paket Keahlian }} & \multicolumn{3}{c|}{$\begin{array}{c}\text { Biaya Pendidikan } \\
\text { (Rp) }\end{array}$} \\
\cline { 2 - 4 } & Kelas X & \multicolumn{1}{c|}{ Kelas XI } & \multicolumn{1}{c|}{ Kelas XII } \\
\hline Akuntansi & $694.572,82$ & $710.597,27$ & $887.732,86$ \\
\hline Perbankan Syariah & $681.239,24$ & $728.629,99$ & $536.110,69$ \\
\hline Administrasi Perkantoran & $780.173,18$ & $817.468,86$ & $877.918,19$ \\
\hline
\end{tabular}


Jurnal Pendidikan Akuntansi Indonesia, Vol. XVI, No. 1, Tahun 2018

Arina Chimaya El Haqqi \& Sukirno

$35-47$

\begin{tabular}{|l|r|r|r|}
\hline Pemasaran & $696.641,58$ & $825.564,05$ & $882.805,55$ \\
\hline Teknik Komputer dan Jaringan & $819.932,31$ & $820.480,83$ & $857.685,65$ \\
\hline Multimedia & $731.140,88$ & $781.584,90$ & $821.996,61$ \\
\hline Rekayasa Perangkat Lunak & $608.705,80$ & $539.634,54$ & $629.397,12$ \\
\hline
\end{tabular}

Berdasarkan

perhitungan

menggunakan Metode Activity Based Costing, biaya tertinggi untuk kelas $\mathrm{X}$ dibebankan pada siswa Paket Keahlian Teknik Komputer dan Jaringan sebesar Rp819.932,31, kelas XI pada siswa Paket Keahlian Pemasaran sebesar Rp825.564,05, dan kelas XII pada siswa Paket Keahlian Akuntansi sebesar 887.732,86. Salah satu faktor yang menyebabkan pembebanan lebih tinggi adalah Paket Keahlian tersebut memiliki rasio perbandingan antara biaya kegiatan belajar mengajar dengan jam belajar yang lebih besar dibandingkan Paket Keahlian lain di tiap tingkat. Hal tersebut menyebabkan pembebanan biaya lebih tinggi pada paket keahlian dengan rasio lebih tinggi.

Biaya terendah untuk kelas X dan XI dibebankan pada siswa Paket Keahlian Rekayasa Perangkat Lunak sebesar Rp608.705,80 dan Rp539.634,54, sedangkan pembebanan biaya terendah kelas XII adalah pada siswa Paket Keahlian Perbankan Syariah sebesar Rp536.110,69. Berdasarkan analisis peneliti, hal ini terjadi karena rasio jumlah biaya yang berkaitan dengan kegiatan belajar mengajar dan jumlah jam belajar lebih kecil. Artinya, biaya yang dibebankan sedikit dan ditanggung oleh siswa dengan proporsi jumlah yang lebih banyak.

Informasi mengenai biaya untuk setiap siswa dapat dilihat dari perhitungan dengan Metode Activity Based Costing dengan melihat pada Lampiran 18. Hasil ini sejalan dengan hasil penelitian Akyol, Tuncal, dan Bayhan (2007), yang menyatakan bahwa Activity Based Costing dapat mengubungkan antara biaya produk dengan informasi produk. Artinya, dengan Activity Based Costing dapat diketahui bagaimana suatu produk diproduksi, waktu yang dibutuhkan, dan dana yang terserap untuk setiap aktivitas.

Hasil perhitungan dapat dibandingkan menjadi dua kategori, yaitu undercosted dan overcosted undercosting (Horngren, Datar, \& Foster, 2008: 161). Undercosted artinya hasil perhitungan menggunakan metode Tradisonal lebih rendah daripada hasil perhitungan menggunakan Metode Activity Based Costing. Overcosted adalah hasil perhitungan menggunakan Metode Tradisonal lebih tinggi daripada hasil perhitungan menggunakan Metode Activity Based Costing. Terdapat sebelas biaya yang masuk kategori undercosted by traditional costing dan sepuluh biaya yang masuk kategori overcosted.

Berikut adalah kategorisasi Biaya Pendidikan berdasarkan selisih perhitungan:

Tabel 6. Perbandingan Hasil Perhitungan Biaya Pendidikan berdasarkan Metode Tradisional dan Activity Based Costing

\begin{tabular}{|c|c|c|c|c|c|}
\hline \multicolumn{2}{|c|}{ Paket Keahlian } & $\begin{array}{c}\text { Metode } \\
\text { Tradisional (Rp) }\end{array}$ & $\begin{array}{c}\text { Metode Activity } \\
\text { Based Costing } \\
(\mathbf{R p})\end{array}$ & $\begin{array}{c}\text { Selisih } \\
(\mathbf{R p})\end{array}$ & Keterangan \\
\hline \multirow{3}{*}{$\mathrm{X}$} & AK & $694.274,59$ & $694.572,82$ & $(298,23)$ & Undercosted \\
\cline { 2 - 6 } & PS & $684.968,85$ & $681.239,24$ & $3.729,61$ & Overcosted \\
\cline { 2 - 6 } & AP & $690.191,25$ & $780.173,18$ & $(89.981,93)$ & Undercosted \\
\hline
\end{tabular}




\begin{tabular}{|c|c|c|c|c|c|}
\hline \multicolumn{2}{|c|}{ Paket Keahlian } & \multirow{2}{*}{$\begin{array}{c}\text { Metode } \\
\text { Tradisional (Rp) }\end{array}$} & \multirow{2}{*}{$\begin{array}{c}\begin{array}{c}\text { Metode Activity } \\
\text { Based Costing } \\
\text { (Rp) }\end{array} \\
696.641,58 \\
\end{array}$} & \multirow{2}{*}{$\begin{array}{c}\begin{array}{c}\text { Selisih } \\
\text { (Rp) }\end{array} \\
2.066,29 \\
\end{array}$} & \multirow{2}{*}{$\begin{array}{c}\text { Keterangan } \\
\text { Overcosted }\end{array}$} \\
\hline & PM & & & & \\
\hline & TK & $695.767,17$ & $819.932,31$ & $(124.165,14)$ & Undercosted \\
\hline & MM & $695.292,37$ & $731.140,88$ & $(35.848,51)$ & Undercosted \\
\hline & RPL & $695.586,21$ & $608.705,80$ & $86.880,41$ & Overcosted \\
\hline \multirow{7}{*}{ XI } & $\mathrm{AK}$ & $781.185,34$ & $710.597,27$ & $70.588,07$ & Overcosted \\
\hline & PS & $771.730,16$ & $728.629,99$ & $43.100,17$ & Overcosted \\
\hline & $\mathrm{AP}$ & $777.028,43$ & $817.468,86$ & $(40.440,42)$ & Undercosted \\
\hline & $\mathrm{PM}$ & $785.771,16$ & $825.564,05$ & $(39.792,89)$ & Undercosted \\
\hline & TK & $782.599,64$ & $820.480,83$ & $(37.881,18)$ & Undercosted \\
\hline & MM & $782.053,68$ & $781.584,90$ & 468,78 & Overcosted \\
\hline & RPL & $782.423,39$ & $539.634,54$ & $242.788,85$ & Overcosted \\
\hline \multirow{7}{*}{ XII } & AK & $837.187,83$ & $887.732,86$ & $(50.545,03)$ & Undercosted \\
\hline & PS & $652.085,24$ & $536.110,69$ & $115.974,54$ & Overcosted \\
\hline & $\mathrm{AP}$ & $833.155,33$ & $877.918,19$ & $(44.762,86)$ & Undercosted \\
\hline & PM & $841.671,94$ & $882.805,55$ & $(41.133,60)$ & Undercosted \\
\hline & TK & $836.029,31$ & $857.685,65$ & $(21.656,34)$ & Undercosted \\
\hline & MM & $835.632,78$ & $821.996,61$ & $13.636,17$ & Overcosted \\
\hline & RPL & $660.782,43$ & $629.397,12$ & $31.385,32$ & Overcosted \\
\hline
\end{tabular}

Secara umum, perbedaan dari kedua metode dapat dilihat dari dasar alokasi overhead, cost pool, homogenitas biaya, dan tahap perhitungan sesuai dengan teori yang dungkapkan oleh . Perbedaan tersebut diuraikan dalam pembahasan berikut.

Dasar alokasi overhead pada Metode Tradisional adalah menggunakan satu dasar tarif tunggal, yaitu jumlah siswa. pada perhitungan menggunakan Metode Activity Based Costing, biaya overhead yang dikategorikan dalam Aktivitas Sekunder memiliki dasar alokasi yang berbeda, tergantung pada objek biaya yang menggunakan biaya tersebut.

Dalam perhitungan Metode Tradisional, biaya dikelompokkan dalam dua cost pool, yaitu 1) biaya yang dibebankan secara langsung kepada siswa, dan 2) biaya yang dikelompokkan dalam biaya overhead. Dalam perhitungan berdasarkan metode Activity Based Costing, ada 26 kelompok biaya seperti yang disajikan pada Tabel 57. Kelompok biaya tersebut muncul karena setiap kelompok biaya pada perhitungan berdasarkan Activity Based Costing memiliki penggerak sumber daya dan biaya yang berbeda-beda.

Homogenitas biaya pada perhitungan berdasarkan Metode Activity Based Costing lebih banyak daripada dalam perhitungan berdasarkan Metode Tradisional. Pada perhitungan berdasarkan Metode Tradisional, biaya dikelompokkan menjadi dua, yaitu biaya langsung dan tidak langsung. Biaya Langsung dibebankan secara langsung kepada siswa, sedangkan biaya overhead dibebankan berdasarkan tarif tunggal. Pada perhitungan berdasarkan Metode Activity Based Costing, biaya yang ada dikelompokkan menjadi 26 jenis aktivitas.

Perhitungan berdasarkan Metode Tradisional dalam penelitian ini melewati dua tahap, yaitu tahap identifikasi jenis 
biaya dan tahap perhitungan tarif overhead. Pada tahap identifikasi biaya, biaya dikelompokkan menjadi Biaya Langsung dan Biaya Tidak Langsung. Pada tahap kedua dilakukan penentuan tarif Biaya Tidak Langsung yang dihitung berdasarkan jumlah siswa.

Perhitungan Metode Activity Based Costing dalam penelitian ini melewati tiga tahap utama, yaitu identifikasi Aktivitas dan atribut Aktivitas serta Pembebanan Biaya pada Aktivitas, pembebanan Aktivitas Sekunder ke Aktivitas lain, dan pembebanan Biaya pada Produk. Tiga tahap tersebut dipecah menjadi empat tahap dengan menambahkan tahap pengumpulan ke dalam Activity Cost Pool untuk menyederhanakan perhitungan tarif aktivitas (Hansen \& Mowen, 2009: 186).

Perbandingan hasil perhitungan menggunakan kedua metode tidak konstan. Artinya, hasil perhitungan dengan Metode tradisional tidak selalu lebih besar dibandingkan dengan hasil perhitungan menggunakan Metode Activity Based Costing maupun sebaliknya. Hasil penelitian ini sejalan dengan hasil penelitian oleh Coskun \& Yilmaz (2013) dan Akyol, Tuncel, \& Bayhan (2007) yang menemukan bahwa hasil perbandingan dua metode bisa jadi lebih kecil, lebih besar, atau hampir sama.

\section{SIMPULAN DAN SARAN Simpulan}

Hasil penelitian menunjukkan bahwa tidak terdapat perbedaan yang berarti antara biaya yang dihitung menggunakan Metode Tradisional dan Metode Activity Based Costing.

Hasil perhitungan Biaya Pendidikan menggunakan Metode Tradisional per Siswa per bulan pada setiap Paket Keahlian untuk Kelas X, XI, dan XII secara berturut-turut yaitu 1) Akuntansi Rp694.274,59, Rp781.185,34, dan Rp837.187,83, 2) Perbankan Syariah Rp684.968,85, Rp771.730,16, dan Rp652.085,24, 3) Administrasi
Perkantoran Rp690.191,25, Rp777.028,43, Rp833.155,33, 4) Pemasaran Rp698.707,87, Rp785.771,16, dan Rp841.671,94, 5) Teknik Komputer dan Jaringan Rp695.767,17, Rp782.599,64, dan Rp836.029,31， 6) Multimedia Rp695.292,37， Rp782.053,68， dan Rp835.632,78, 7) Rekayasa Perangkat Lunak Rp95.586,2, Rp782.423,39, dan Rp660.782,43.

Hasil perhitungan Biaya Pendidikan menggunakan Metode Activity Based Costing per Siswa per bulan pada setiap Paket Keahlian untuk Kelas X, XI, dan XII secara berturut-turut yaitu 1) Akuntansi Rp694.572,82, Rp710.597,27, dan Rp887.732,86, 2) Perbankan Syariah Rp681.239,24, Rp728.629,99, dan Rp536.110,69, 3) Administrasi Perkantoran Rp780.173,18, Rp817.468,86, dan Rp877.918,19, 4) Pemasaran Rp696.641,58, Rp825.564,05, dan Rp882.805,55, 5) Teknik Komputer dan Jaringan Rp819.932,31, Rp820.480,83, dan Rp857.685,65, 6) Multimedia Rp731.140,88, Rp781.584,90, dan Rp821.996,61, 7) Rekayasa Perangkat Lunak Rp608.705,80, Rp539.634,54, dan Rp629.397,12.

Hasil perbandingan menunjukkan bahwa terdapat sebelas Biaya Pendidikan per Siswa yang undercosted dan sepuluh Biaya Pendidikan per Siswa yang overcosted terhadap hasil perhitungan menggunakan Metode Tradisional. Dari penelitian diketahui bahwa Metode Activity Based Costing menyajikan informasi konsumsi biaya per siswa pada setiap paket keahlian dan tingkat yang lebih akurat dan rinci dibandingkan dengan perhitungan menggunakan Metode Tradisional.

\section{Saran}

Bagi pemerintah, pemerintah dapat menggunakan hasil perhitungan berdasarkan Metode Activity Based Costing sebagai dasar untuk menentukan jumlah Bantuan Operasional Selolah yang diberikan kepada siswa. 
Bagi sekolah, 1) informasi detail mengenai penggunaan sumber daya harus dimiliki oleh sekolah mengingat pentingnya informasi tersebut sebagai dasar pembebanan ke Aktivitas apabila sekolah ingin menerapkan Metode Activity Based Costing dalam perhitungan biaya, 2) Metode Activity Based Costing tidak bisa dikatakan lebih baik maupun lebih buruk daripada Metode Tradisional, namun perhitungan dengan Metode Activity Based Costing menghasilkan hasil perhitungan yang lebih akurat serta memuat informasi penggunaan aktivitas yang lebih detail, sehingga akan lebih baik apabila sekolah mulai menerapkan metode perhitungan berdasarkan aktivitas, 3) sekolah harus memiliki informasi yang detail mengenai jumlah pemasukan yang akan diterima selama tahun berjalan, agar tidak membebankan biaya teralu besar atau terlalu kecil kepada siswa.

Bagi peneliti selanjutnya, 1) sebaiknya mempertimbangkan ketersediaan data di sekolah yang akan dijadikan sebagai subjek penelitian, 2) sebaiknya mencari subjek dengan penggunaan tahun anggaran dan tahun ajaran yang sama untuk mempermudah proses perhitungan, dan 3) mengusahakan perolehan rincian data gaji guru dan realisasi anggaran agar dapat mengungkapkan biaya dengan lebih akurat.

\section{DAFTAR PUSTAKA}

Abu-Tapanjeh, A. M. (2008). ActivityBased Costing Approach to Handle the Uncertainty Costing of Higher Educational Institutions: Perspective from an Academic College. Journal of King Abdul Aziz University, 2, 29-57.

Akyol, D. E, Tuncen, G., \& Bayhan, G. M. (2007). A Comparative Analysis of Activity-Based Costing and Traditional Costing. International Scholarly and Scientific Research \& Innovation, Vol 1, 3, 136-139.
Coskun, A. \& Yilmaz, M. (2013). Pricing Decisions in Educational Institutions: An Activity Based Approach. Procedia-Soccial and Behavioral Sciences, 106, 2112-2118.

Hansen, D. R. \& Mowen, M. M. (2009). Akuntansi Manajerial. (Terjemahan Deny Arnos Kwary). Jakarta: Penerbit Salemba Empat. (Edisi asli diterbitkan tahun 2007 oleh Cengage Learning Asia Pte Ltd. 5 Shenton Way Singapore).

Horngren, C. T., Datar, S. M., \& Foster, G. (2008). Akuntansi Biaya Jilid 1. (Terjemahan P.A. Lestari). Jakarta: PT Gelora Aksara Pratama. (Edisi asli diterbitkan tahun 2006 oleh Pearson Education Inc. Upper Saddle River, New Jersey).

Maelah, R., Amir, A. M., Ahmad, A., et al. (2011). Cost per Students Using ABC Aproach. International Proceedings of Economics Develompment and Research Vol 9, 7, 40-45.

Matin. (2013). Dasar-Dasar Perencanaan Pendidikan. Jakarta: PT RajaGrafindo Persada.

Mulyono. (2010). Konsep Pembiayaan Pendidikan. Yogyakarta: Ar-Ruzz Media.

Muslim, H. (2015). Kedudukan Uang Jemputan dalam Perkawinan Bajapuik pada Masyarakat Minangkabau Pariaman ditinjau dari Undang-Undang Nomor 1 Tahun 1974 tentang Perkwainan. Skripsi. Universitas Sumatera Utara.

Prasetya, B. \& Jannah, L.M. (2013). Metode Penelitian Kuantitatif: Teori dan Aplikasinya. Depok: PT Grafindo Persada. 
Purwanto. (2015). Metodologi Penelitian Kuantitatif untuk Psikologi dan Pendidikan. Yogyakarta: Pustaka Belajar.

Raiborn, C. A \& Kinny, R. K. (2011). Akuntansi Biaya: Dasar dan Pengembangan. (Terjemahan Rahmat Hilman). Jakarta: Salemba Empat. (Edisi asli diterbitkan tahun 2009 oleh Cengage Learning Asia Pte Ltd 5 Shenton Way Singapore).

Rumampuk, M. S. (2013). Perbandingan Perhitungan Harga Pokok Produk Menggunakan Metode Activity Based Costing dan Metode Konvensional Pada Usaha Peternakan Ayam CV. Kharis Di Kota Bitung. Jurnal Riset Ekonomi, Manajemen, Bisnis, dan Akuntansi, 1, 637-645.

Sukmadinata, N. S. (2015). Metode Penelitian Pendidikan. Bandung: PT Remaja Rosdakarya.

Supriadi, D. (2004). Satuan Biaya Pendidikan Dasar dan Menengah. Bandung: PT Remaja Rosdakarya. 